\title{
The influence of Pilates participants' empirical values on their emotional responses and behavioral intentions
}

\author{
Su Yeon Roh* \\ Department of Exercise Rehabilitation and Welfare, College of Health Science, Gachon University, Incheon, Korea
}

This study aimed to investigate the relationship between the empirical value of Pilates participants and their emotional response and behavioral intention. For this study, 286 participants who participated in Pilates classes in Seoul and Gyeonggi-do in 2019 were selected using the convenience sampling method. For data processing, frequency, exploratory factor, reliability, correlation, and multiple regression analyses were performed using PASW ver. 23.0. The empirical values of the Pilates participants had a significant effect on their emotional response and behavioral intention. The emotional responses of the Pilates participants also had a significant effect on their behavioral intention. In summary, Pilates instructors, therefore, try to help the participants form positive experiences and emotional responses to induce participants' continuous participation.

Keywords: Pilates, Participants, Empirical value, Emotional response, Behavioral intention

\section{INTRODUCTION}

In the past, with "Faster, Higher, and Stronger" as their slogan, the public preferred to do fast exercise, which requires a muscular body. Recently, however, sports that put emphasis on slow exercise, such as yoga and Pilates, and that seek not only physical health but also mental balance, are fast gaining popularity among the public (Maguire, 2001; Roh, 2018a).

In the process of such change, Pilates is gaining public attention as a representative slow exercise. Introduced by Joseph H. Pilates of Germany in the early 1900s, Pilates emphasizes mental concentration, restrained flexibility, and mind-body harmony, and promotes motor activity of even the smaller muscles that are not used often, all without moving the body much, thereby helping one achieve a balanced posture and body shape. In addition, Pilates is a static exercise that helps contemporary people overcome their spatial constraints and relieve their stress by providing them with psychological stability, such as through meditation (Roh, 2018b). Above all, Pilates is loved by many women as it helps correct their posture, strengthen their muscles, and increase their flexibility, thereby helping them maintain their body's harmony and beauty (Cruz-Ferreira et al., 2011; Joseph and Simona, 2004).

In addition to the positive effects of the Pilates exercises, many people pursue their own unique emotional stimulation as they consider the direct or indirect experience of Pilates very important (Nam et al., 2009). In other words, the more materially abundant a person is, the more important time and mental abundance will become for him, and the greater a person's desire to improve the quality of his life is, the more attention he will pay to his experiential consumption (Park and Sung, 2011).

In other words, the Pilates participants value experiential consumption through activities, as well as the harmonious development of their body and spirit through exercise. Experiential consumption, instead of material possession, is the main purpose of the experience itself, and the Pilates participants enjoy positive emotions like pleasure, emotional uplift, joy, and fulfillment during the experience (Jung and Lee, 2009). These feelings have a significant impact on experiential consumption and consumer behavior.

According to Lee and Lim (2002), emotion is defined as a direct experience through consumption activities, where consumption is
${ }^{\star}$ Corresponding author: Su Yeon Roh (iD https://orcid.org/0000-0001-5573-5870 Department of Exercise Rehabilitation and Welfare, College of Health Science, Gachon University, 191 Hambakmeo-ro, Yeonsu-gu, Incheon 21936, Korea E-mail: rsypilates@naver.com

Received: October 8, 2019 / Accepted: November 11, 2019
This is an Open Access article distributed under the terms of the Creative Commons Attribution Non-Commercial License (http://creativecommons.org/licenses/by-nc/4.0/) which permits unrestricted non-commercial use, distribution, and reproduction in any medium, provided the original work is properly cited. 
defined as a concept that includes only the purchase and utilization of a product or service after its purchase. For Pilates participants, consumption can consist in a Pilates experience. Therefore, the values of Pilates participants can influence their emotions, which can be inferred to lead to their subsequent behavioral intentions.

In a study by Kirsch (1985), behavioral intention was closely related to behavior with actual experience, and this behavioral intention was highly correlated with actual behavior stemming from experience. Therefore, behavioral intention can be seen as an important predictor of a person's future behavior.

The theory of behavioral intention suggests that a consumer's direct experience is instilled in his memory and ultimately direct impacts his purchase behavior. In other words, if the value experienced by a consumer through a sports activity like Pilates is shaped by positive emotions, it can also affect the consumer's consumption behavior. The purpose of this study, therefore, was to investigate how the empirical values of Pilates participants influence their emotional and behavioral intentions. Below are the specific hypotheses that were established in this study to achieve its research purpose.

(a) The empirical value of the Pilates participants will affect their emotional response.

(b) The empirical value of the Pilates participants will affect their behavioral intention.

(c) The emotional response of the Pilates participants will affect their behavioral intention.

\section{MATERIALS AND METHODS}

\section{Research subjects}

For this study, 300 participants who regularly participated in Pilates classes in Seoul and Gyeonggi-do were selected using the convenience sampling method. The data of a total of 286 subjects were analyzed in the actual analysis, except for those of 14 subjects who were considered to have provided unfaithful survey responses. The demographic characteristics of the study participants are shown in Table 1.

\section{Questionnaire}

The survey tool that was used was a questionnaire. The questionnaire consisted of 34 items: four on the respondent's demographic characteristics, 12 on empirical value, 10 on emotional response, and eight on behavioral intention. For empirical value, the questionnaire developed by Kulviwat et al. (2007) was modified and supplemented for the purpose of this study. In this study, a
Table 1. Pilates participants' characteristics

\begin{tabular}{lr}
\hline Characteristic & No. (\%) \\
\hline Sex & \\
Male & $47(16.4)$ \\
Female & $239(83.6)$ \\
Age (yr) & \\
$<30$ & $139(48.6)$ \\
$30-40$ & $89(31.1)$ \\
$\geq 40$ & $58(20.3)$ \\
Pilates participation period $(y r)$ & \\
$<1$ & $71(24.8)$ \\
$1-3$ & $90(31.5)$ \\
$3-5$ & $78(27.3)$ \\
$\geq 5$ & $47(16.4)$ \\
Education level & \\
High school graduate & $33(11.5)$ \\
University student & $88(30.8)$ \\
University graduate & $132(46.2)$ \\
Graduate school degree & $33(11.5)$ \\
\hline
\end{tabular}

questionnaire consisting of three items on consumer usefulness, three items on aesthetic value, three items on service excellence, and three items on playfulness value was used. For the questions on emotional response, the emotional response scale used by George et al. (2015) was modified and supplemented for the purpose of this study. The subvariables were pleasure (four questions), arousal (three questions), and domination emotion (three questions). For the questions on behavioral intention, the scale that was used in the work of Donovan and Rossiter (1982) was modified and complemented to serve the purpose of this study. The subvariables were exploration intention (three items), word-ofmouth intention (three items), and re-experience intention (two items). Each question was designed to be answered based on a 5-point Likert scale.

\section{Validity and reliability of the questionnaire}

Exploratory factor analysis was conducted to determine the validity and reliability of the questionnaire, and the Cronbach a value was calculated to secure the reliability of the scale.

Four factors were extracted as a result of the 12-question factor analysis on empirical value. The factor load of consumer usefulness was $0.754-0.826$, that of aesthetic value was $0.689-0.878$, that of service excellence was $0.596-0.851$, and that of fun value was $0.577-0.713$. They are all considered valid measurements, and the results are presented in Table 2. In addition, the Cronbach a value of experience value was $0.874-0.843$, suggesting that it was 
Table 2. Exploratory factor analysis of empirical value

\begin{tabular}{lcccc}
\hline Item & $\begin{array}{c}\text { Consumer } \\
\text { usefulness }\end{array}$ & $\begin{array}{c}\text { Aesthetic } \\
\text { value }\end{array}$ & $\begin{array}{c}\text { Service } \\
\text { excellence }\end{array}$ & $\begin{array}{c}\text { Playfulness } \\
\text { value }\end{array}$ \\
\hline 1 & 0.826 & 0.213 & 0.015 & 0.007 \\
2 & 0.754 & -0.085 & 0.156 & 0.250 \\
3 & 0.803 & 0.214 & -0.112 & 0.164 \\
4 & 0.231 & 0.689 & 0.265 & 0.285 \\
5 & 0.083 & 0.878 & 0.228 & 0.131 \\
6 & 0.054 & 0.798 & 0.032 & 0.231 \\
7 & 0.245 & 0.098 & 0.111 & 0.577 \\
8 & 0.116 & 0.126 & 0.212 & 0.613 \\
9 & 0.154 & 0.175 & 0.078 & 0.713 \\
10 & 0.284 & 0.201 & 0.596 & 0.352 \\
11 & 0.154 & 0.123 & 0.851 & 0.078 \\
12 & 0.265 & 0.214 & 0.772 & 0.031 \\
Eigenvalues & 2.226 & 2.138 & 1.899 & 1.589 \\
Variance (\%) & 22.260 & 21.380 & 18.990 & 15.890 \\
Accumulation (\%) & 22.260 & 43.640 & 62.630 & 78.520 \\
Cronbach $\alpha$ & 0.812 & 0.802 & 0.843 & 0.794 \\
\hline
\end{tabular}

above the reliable level.

Three factors were extracted as a result of the factor analysis of the 10 items on emotional response. The factor load of pleasure was $0.779-0.932$, that of the arousal factor was $0.784-0.881$, and that of the domination emotion was $0.559-0.875$. They are all considered valid measurements, and the results are presented in Table 3. In addition, the Cronbach a value of experience value was $0.720-0.821$, suggesting that it was above the reliable level.

Three factors were extracted as a result of the 8 -factor factor analysis on behavioral intention. The factor load of exploration intention was $0.858-0.923$, that of word-of-mouth intention was $0.726-0.816$, and that of re-experience intention was $0.791-$ 0.886 . They are all considered valid measurements, and the results are presented in Table 4. In addition, the Cronbach a value of experience value was $0.770-0.883$, suggesting that it was above the reliable level.

\section{Data analysis}

To achieve the purpose of this study, data processing was performed as follows, using the IBM SPSS Statistics ver. 23.0 (IBM Co., Armonk, NY, USA). First, frequency, reliability, and correlation analyses were performed using IBM SPSS ver. 23.0 to investigate the demographic characteristics of the survey subjects and to verify the questionnaire errors. Second, multiple regression analysis was performed using the same program (IBM SPSS ver. 23.0) to verify the research model and hypotheses that were established
Table 3. Exploratory factor analysis of emotional response

\begin{tabular}{lrrc}
\hline Item & Pleasure & Arousal & Domination emotion \\
\hline 1 & 0.932 & 0.125 & 0.212 \\
2 & 0.815 & 0.088 & 0.271 \\
3 & 0.821 & 0.079 & 0.234 \\
4 & 0.779 & 0.035 & 0.261 \\
5 & 0.123 & 0.784 & 0.151 \\
6 & 0.064 & 0.881 & 0.068 \\
7 & 0.055 & 0.821 & 0.103 \\
8 & 0.191 & 0.154 & 0.654 \\
9 & 0.233 & 0.068 & 0.559 \\
10 & 0.168 & 0.081 & 0.875 \\
Eigenvalues & 2.954 & 2.131 & 1.785 \\
Variance (\%) & 29.540 & 21.310 & 17.850 \\
Cumulative (\%) & 29.540 & 50.850 & 68.700 \\
Cronbach $\alpha$ & 0.771 & 0.720 & 0.821 \\
\hline
\end{tabular}

Table 4. Exploratory factor analysis of behavior intention

\begin{tabular}{lccc}
\hline Item & $\begin{array}{c}\text { Exploration } \\
\text { intention }\end{array}$ & $\begin{array}{c}\text { Word-of-mouth } \\
\text { intention }\end{array}$ & $\begin{array}{c}\text { Re-experience } \\
\text { intention }\end{array}$ \\
\hline 1 & 0.923 & 0.069 & 0.244 \\
2 & 0.902 & 0.159 & 0.148 \\
3 & 0.858 & 0.224 & 0.236 \\
4 & 0.104 & 0.751 & 0.225 \\
5 & 0.115 & 0.726 & 0.208 \\
6 & 0.195 & 0.816 & 0.174 \\
7 & 0.232 & 0.226 & 0.886 \\
8 & 0.326 & 0.209 & 0.791 \\
Eigenvalues & 2.624 & 1.932 & 1.672 \\
Variance (\%) & 26.240 & 19.320 & 16.720 \\
Cumulative (\%) & 26.240 & 45.560 & 62.280 \\
Cronbach's $\alpha$ & 0.826 & 0.883 & 0.770 \\
\hline
\end{tabular}

in this study.

\section{RESULTS}

\section{Correlation analysis}

The Pearson correlation coefficient was calculated before analyzing the effects of the empirical value of the Pilates participants on their emotional response and behavioral intention based on the results of the factor analysis, to confirm the degree of satisfaction of the discriminant validity between the factors for the one-dimensionality identified factors shown in Table 5. The correlation coefficient was less than $0.800(0.099-0.581)$, which is the reference coefficient of multicollinearity. 
Table 5. Correlation analyses among the variables

\begin{tabular}{|c|c|c|c|c|c|c|c|c|c|c|}
\hline Variable & 1 & 2 & 3 & 4 & 5 & 6 & 7 & 8 & 9 & 10 \\
\hline CU & 1 & & & & & & & & & \\
\hline AV & $0.435^{* *}$ & 1 & & & & & & & & \\
\hline SE & $0.375^{* *}$ & $0.374^{* *}$ & 1 & & & & & & & \\
\hline PV & $0.435^{* *}$ & $0.387^{* *}$ & $0.554^{* *}$ & 1 & & & & & & \\
\hline Pleasure & $0.569^{* *}$ & $0.294^{* *}$ & $0.246^{* *}$ & $0.459^{* *}$ & 1 & & & & & \\
\hline Arousal & 0.103 & $0.157^{*}$ & $0.198^{* *}$ & $0.283^{* *}$ & $0.228^{* *}$ & 1 & & & & \\
\hline $\mathrm{DE}$ & $0.249^{* *}$ & $0.147^{*}$ & $0.228^{* *}$ & $0.267^{* *}$ & $0.241^{* *}$ & $0.464^{* *}$ & 1 & & & \\
\hline El & $0.146^{*}$ & 0.106 & $0.188^{* *}$ & $0.197^{* *}$ & 0.099 & $0.325^{* *}$ & $0.581^{* *}$ & 1 & & \\
\hline WMI & $0.201^{* *}$ & $0.209^{* *}$ & $0.241^{* *}$ & $0.378^{* *}$ & $0.233^{* *}$ & $0.558^{* *}$ & $0.449^{* *}$ & $0.466^{* *}$ & 1 & \\
\hline REI & $0.231^{* *}$ & $0.264^{* *}$ & $0.229^{* *}$ & $0.351^{* *}$ & $0.289^{* *}$ & $0.441^{* *}$ & $0.367^{* *}$ & $0.337^{* *}$ & $0.544^{* *}$ & 1 \\
\hline
\end{tabular}

$\mathrm{CU}$, consumer usefulness; $\mathrm{AV}$, aesthetic value; $\mathrm{SE}$, service excellence; PV, playfulness value; $\mathrm{DE}$, dominance emotion; El, exploration intention; WMI, word-of-mouth intention; REl, re-experience intention.

${ }^{*} P<0.05$. ${ }^{* *} P<0.01$.

Table 6. Multiple regression between the Pilates participants' experience value and emotional response

\begin{tabular}{|c|c|c|c|c|c|c|}
\hline \multirow{2}{*}{ Variable } & \multicolumn{2}{|c|}{ Pleasure } & \multicolumn{2}{|c|}{ Arousal } & \multicolumn{2}{|c|}{ Domination } \\
\hline & Beta & $t$-value & Beta & $t$-value & Beta & $t$-value \\
\hline CU & 0.513 & $9.325^{* * *}$ & -0.077 & -1.021 & 0.152 & $2.078^{*}$ \\
\hline AV & -0.098 & -0.413 & 0.042 & 0.559 & -0.031 & -0.521 \\
\hline SE & 0.141 & $2.412^{* *}$ & 0.039 & 0.496 & 0.084 & 1.091 \\
\hline PV & 0.336 & $5.558^{* * *}$ & 0.291 & $3.681^{* * *}$ & 1.131 & 1.844 \\
\hline$R^{2}$ & \multicolumn{2}{|c|}{0.442} & \multicolumn{2}{|c|}{0.085} & \multicolumn{2}{|c|}{0.081} \\
\hline
\end{tabular}

CU, consumer usefulness; AV, aesthetic value; SE, service excellence; PV, playfulness value

${ }^{*} P<0.05 .{ }^{* *} P<0.01 .{ }^{* * *} P<0.001$

Effect of the empirical value of the Pilates participants on their emotional response

Multiple regression analysis was performed to investigate the effect of the empirical value of the Pilates participants on their emotional response. Table 6 shows that the empirical value of the Pilates participants influence their pleasure, breathability, and dominance, which are subvariables of emotional response. Specifically, the explanatory power for the fluctuation of pleasure, a subvariable of emotional response, was $44.2 \%$; that for the fluctuation of ventilation was $8.5 \%$; and that for the fluctuation of control was $8.1 \%$. To investigate the relationship between empirical value and emotional response, multiple regression analysis was performed.

\section{Effect of the empirical value of the Pilates participants on their behavioral intention}

The results of the multiple regression analysis designed to investigate the effect of the empirical values of the Pilates partici-
Table 7. Multiple regression analysis of the Pilates participants' experience value and behavioral response

\begin{tabular}{lccccccccc}
\hline \multirow{2}{*}{ Variable } & \multicolumn{2}{c}{ El } & & \multicolumn{2}{c}{ WMl } & & \multicolumn{2}{c}{ REI } \\
\cline { 2 - 3 } \cline { 8 - 9 } & Beta & t-value & & Beta & $t$-value & & Beta & $t$-value \\
\hline CU & 0.043 & 0.568 & & 0.031 & 0.397 & & 0.031 & 0.452 \\
AV & 0.021 & 0.260 & & 0.048 & 0.551 & & 1.121 & 1.778 \\
SE & 0.082 & 1.098 & & 0.024 & 0.311 & & 0.024 & 0.362 \\
PV & 0.079 & 1.008 & & 0.284 & $3.741^{* * *}$ & & 2.412 & $3.121^{* *}$ \\
$R^{2}$ & \multicolumn{2}{c}{ R2 } & & \multicolumn{2}{c}{0.107} & & \multicolumn{2}{c}{0.101}
\end{tabular}

$C U$, consumer usefulness; $A V$, aesthetic value; SE, service excellence; PV, playfulness value El, exploration intention; WMI, word-of-mouth intention; REl, re-experience intention.

${ }^{* *} P<0.01$. ${ }^{* *} P<0.001$

pants on their behavioral intention are shown in Table 7. The empirical value of the Pilates participants did not appear to have affected their intention, which area subvariables of behavioral intention, accounting for only $2.1 \%$ of the variance. Their empirical values, however, influenced their word-of-mouth and re-experience intentions.

\section{Effect of the emotional response of the Pilates participants on their behavioral intention}

The results of the multiple regression analysis performed to investigate the influence of the emotional response of the Pilates participants on their behavioral intention are shown in Table 8 . Specifically, the emotional response of the Pilates participants was found to have had a significant effect on their exploration, wordof-mouth, and re-experience intentions, which are subvariables of behavioral intention. The explanatory power for search intention was $40.7 \%$, that for word-of-mouth intention was $42.9 \%$, and that for re-experience intention was $29.1 \%$. 
Table 8. Multiple regression between the Pilates participants' emotional response and behavioral intention

\begin{tabular}{lcccccccc}
\hline \multirow{2}{*}{ Variable } & \multicolumn{2}{c}{ El } & & \multicolumn{2}{c}{ WMI } & & \multicolumn{2}{c}{ REI } \\
\cline { 2 - 3 } \cline { 7 - 8 } & beta & $t$-value & & beta & $t$-value & & beta & $t$ tvalue \\
\hline Pleasure & -0.051 & -0.099 & & 0.088 & 1.711 & & 0.151 & $2.746^{* *}$ \\
Arousal & 0.096 & 1.679 & & 0.466 & $8.361^{* * *}$ & & 0.374 & $5.889^{* * *}$ \\
Domination & 0.612 & $10.512^{* * *}$ & & 0.285 & $4.774^{* * *}$ & & 0.171 & $2.849^{* *}$ \\
$R^{2}$ & 0.407 & & 0.429 & & 0.281 \\
\hline
\end{tabular}

El, exploration intention; WMI, word-of-mouth intention; REl, re-experience intention.

${ }^{* *} P<0.01$. ${ }^{* *} P<0.001$.

\section{DISCUSSION}

The purpose of this study was to investigate the relationships among the empirical value, emotional response, and behavioral intention of Pilates participants. To achieve this goal, the data from 286 people who regularly participated in Pilates classes in Seoul and Gyeonggi-do were analyzed. For data processing, frequency, exploratory factor, reliability, correlation, and multiple regression analyses were performed using IBM SPSS ver. 23.0. In this chapter, the previously presented study results will be discussed in greater detail.

First, the empirical value of the Pilates participants was found to have had a significant effect on their emotional response. In relation to these findings, Jeong et al. (2008) suggested a relationship between empirical value and emotional response. The subvariables of empirical value, aesthetics, and entertainment had a significant effect on ventilation. In addition, the study of Jung and Lee (2009) also showed a significant effect on the relationship between the value of consumption and pleasure in experiential consumption. Ahn and Lee (2011) also found that the empirical value factors of visual appeal, entertainment, and daily escape had a significant effect on emotional response. Therefore, the results of this study support the results of the aforementioned previous studies, suggesting that Pilates participants are primarily concerned with the Pilates experience itself, and can be seen as consumers of experiential consumption. They also seek to enjoy and benefit from their experiences, and to enjoy their own emotions stemming from their Pilates experience.

Second, the empirical value of the Pilates participants was found to have had a significant effect on behavioral intention. In relation to this finding, Parasuraman and Grewal (2000) found in their study on the structural model of value, satisfaction, and behavioral intention that value is not only the choice behavior of the prepurchase customers but is also the postpurchase satisfaction, intention, and recommendation. In addition, the studies by Jung and Lee (2009) and Chang and Ahn (2016) have shown that empirical values have a significant effect not only on behavioral intention but also on loyalty. Therefore, the results of this study support the results of these previous studies. Taken together, the results show that Pilates helps its participants obtain unique experiences through education, and that if values of satisfaction beyond the experience are formed, a favorable attitude towards Pilates will be developed, and the continuous participation in and re-experience of Pilates will be increased.

Third, the emotional response of the Pilates participants was found to have had a significant effect on their behavioral intention. In relation to this finding, Bagozzi et al. (1999) found that positive emotions have a significant effect on the behavioral intentions of positive word-of-mouth, willingness to pay, and transitional behavior. Feelings can be seen as an important variable in the participants' later behavior. In other words, if Pilates participants have positive feelings about their Pilates activities, they will continue to search for Pilates, encourage others to follow their lead, or develop the intention of re-experiencing it. Pilates leaders, therefore, are advised not only to ensure accurate and thorough education but also to try to help the participants form positive feelings after their perceived experiences to induce their continuous participation.

Research was conducted according to the purpose of this study, using appropriate research methods to identify the relationships among the variables. Below are the limitations of this study and the suggestions for subsequent studies.

First, no interviews or observations were conducted to identify the social and psychological characteristics of the participants because the questionnaire was used to investigate the purpose of this study. Therefore, it is suggested that combined qualitative-quantitative research be conducted in the follow-up studies to address the limitation of quantitative research.

Second, the subjects of this study were limited to the Pilates participants in the Seoul-Gyeonggi area. Therefore, the results of this study cannot be generalized or applied to all Pilates participants. In the follow-up study, it is suggested that a greater variety of study subjects be selected.

\section{CONFLICT OF INTEREST}

No potential conflict of interest relevant to this article was reported. 


\section{REFERENCES}

Ahn KH, Lee HN. The effect of perceived shopping value dimensions on attitude toward store, emotional response to store shopping, and store loyalty. Asia Mark J 2011;12:137-164.

Bagozzi RP, Gopinath M, Nyer PU. The role of emotions in marketing. Acad Mark Sci 1999;27:184-206.

Chang IY, Ahn CW. The relationship between sport confidence, exercise passion and re-participation intention of collegiate students participating in the snow ski-class. J Digit Converge 2016;14:473-483.

Cruz-Ferreira A, Fernandes J, Gomes D, Bernardo LM, Kirkcaldy BD, Barbosa TM, Silva A. Effects of Pilates-based exercise on life satisfaction, physical self-concept and health status in adult women. Women Health 2011;51:240-255.

Donovan RJ, Rossiter JR. Store atmosphere: an environmental psychology approach. J Retail 1982;58:34-57.

George E, Marcus W, Russell N, Mackuen M. Measuring emotional response: comparing alternative approaches to measurement. Polit Sci Res Methods 2015;5:733-754.

Jeong SW, Fiore AM, Niehm LS, Lorenz FO. The role of experiential value in online shopping. Internet Res 2008;19:105-124.

Joseph EM, Simona C. Pilates and the powerhouse. J Bodyw Mov Ther 2004;8:122-130.

Jung YH, Lee JH. A comprehensive framework for experiential consumption: the relationship among experience traits, pleasure and guilty, re-experience in experiential consumption. Korean Manag Rev 2009;
38:523-553.

Kirsch I. Response expectancy as a determinant of experience and behavior. Am Psychol 1985;40:1189-1202.

Kulviwat S, Brunner GC, Kumar A, Nasco SA, Clark T. Toward a unified theory of consumer acceptance technology. Psychol Mark 2007;24: 1059-1084.

Lee HS, Lim JH. Measuring the consumption-related emotion construct. Korea Mark Rev 2002;17:55-91.

Maguire JS. Fit and flexible: the fitness industry, personal trainers and emotional service labor. Social Sport J 2001;18:372-402.

Nam SJ, Lee EH, Hwang YS. The perceived body image of adolescent consumers and clothing purchase behavior model according to selfesteem: focused on the effect of perceived mass media commitment and perceived difference in physical condition. Consum Cult Res 2009; 12:123-146

Parasuraman A, Grewal D. The impact of technology on the quality-valueloyalty chain: a research agenda. J Acad Mark Sci 2000;28:168-174.

Park EA, Sung YS. The effect of consumer perceptions on purchase intention on announcement model: focused on perceived body image comparison. Korean J Psychol 2011;2:87-116.

Roh SY. The effects of body image, commitment, and attitude on behavior after purchase of Pilates consumers. J Exerc Rehabil 2018a;14:944-953.

Roh SY. The influence of physical self-perception of female college students participating in Pilates classes on perceived health state and psychological wellbeing. J Exerc Rehabil 2018b;14:192-198. 